\title{
Peroral endoscopic myotomy (POEM) in jackhammer esophagus: a trick of the trade
}

A 69-year-old man presented for evaluation of progressive atypical chest pain. The patient noted 4 years of progressive daily chest pain, regurgitation of food, and intermittent dysphagia. After extensive evaluation, the patient underwent esophageal manometry which led to a diagnosis of jackhammer esophagus characterized by $100 \%$ hypercontractile waves. The patient had minimal symptomatic response to amitriptyline. He was referred for peroral endoscopic myotomy (POEM).

During the procedure, a $1.5-\mathrm{cm}$ mucosal incision was made using a multipurpose knife (Erbe) for an entry point into the submucosal space. The submucosal space was dissected using intermittent injection and dissection with forced coagulation setting. Dissection of the submucosal tunnel was performed down to the level of the gastroesophageal junction and distal to it by $3 \mathrm{~cm}$ ( $\triangleright$ Video 1 ). Dissection of the circular muscle bundle began from $2 \mathrm{~cm}$ distal to the mucosal entry down to the gastroesophageal junction. In addition, full-thickness myotomy was performed in the mid and distal tun- nel. Division of the sphincter muscles was continued toward the stomach until the endoscope passed through the narrow segment of the lower esophageal sphincter ( $\triangleright$ Fig. 1). The mucosal entry site was closed with hemostatic clips. At 1-month follow-up, the patient noted significant improvement in his pain and other symptoms.

The revised Chicago classification recently defined jackhammer esophagus as a hypercontractile esophagus, with at least one contraction with a distal contractile integral $(\mathrm{DCl})$ of at least $8000 \mathrm{mmHg} \cdot \mathrm{s} \cdot \mathrm{cm}$ [1]. Many treatments of jackhammer esophagus have been tried, including oral nitrates, balloon dilation, and surgical myotomy [2]. Recently POEM has been demonstrated as a safe and effective therapeutic modality for the treatment of spastic esophageal disorders [3], and particularly for jackhammer esophagus [4].

\section{Endoscopy_UCTN_Code_TTT_1AO_2AN}

\section{Competing interests}

Michel Kahaleh MD: has received grant support from Boston Scientific, Fujinon, EMcison, Xlumena Inc., W.L. Gore, MaunaKea, Apollo Endosurgery, Cook Endoscopy, ASPIRE Bariatrics, Gl Dynamics, NinePoint Medical, Merit Medical, Olympus and MI Tech. He is a consultant for Boston Scientific, Xlumena Inc., Concordia Laboratories Inc, ABBvie, and MaunaKea Tech.

All other authors have no conflicts of interest to report.

The Authors

Enad Dawod, Monica Saumoy, Ming-Ming Xu, Michel Kahaleh

Division of Gastroenterology and Hepatology, New York Presbyterian Hospital, Weill Cornell Medical College, New York, United States

\section{Corresponding author}

\section{Michel Kahaleh, MD}

Weill Cornell Medical College -

Gastroenterology \& Hepatology, 1305 York Avenue, 4th Floor, New York 10021, United States

Fax: 01-646-962-0110

mkahaleh@gmail.com

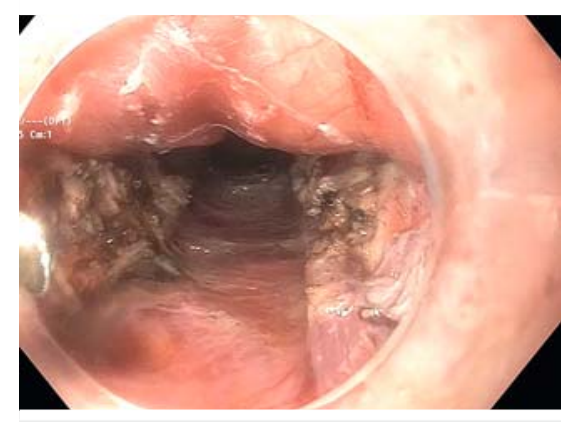

- Fig. 1 Peroral endoscopic myotomy (POEM) for jackhammer esophagus. As the tip of the endoscope reaches the stomach region the submucosal space becomes wider, confirming the completion of the myotomy.

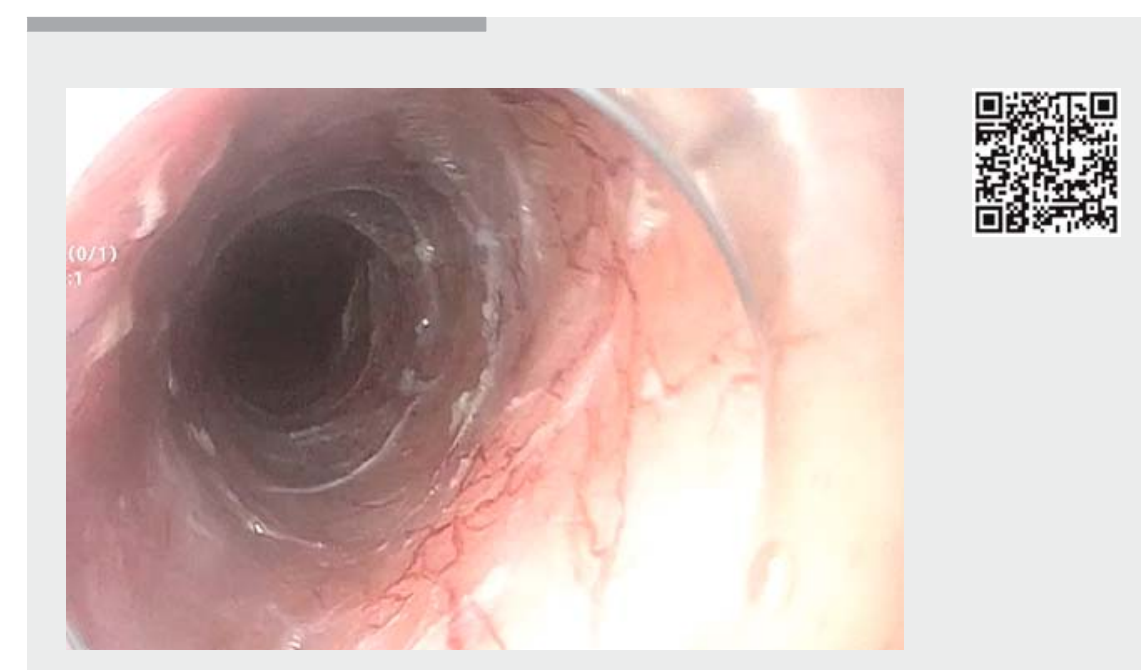

$\checkmark$ Video 1 Peroral endoscopic myotomy (POEM) as a treatment for jackhammer esophagus. 


\section{References}

[1] Bredenoord A], Fox M, Kahrilas PJ et al. Chicago classification criteria of esophageal motility disorders defined in high resolution esophageal pressure topography. Neurogastroenterol Motil 2012; 24 (Suppl. 01): $57-65$

[2] Valdovinos MA, Zavala-Solares MR, CossAdame E. Esophageal hypomotility and spastic motor disorders: current diagnosis and treatment. Curr Gastroenterol Rep 2014; 16: 421

[3] Khan MA, Kumbhari V, Ngamruengphong $S$ et al. Is POEM the answer for management of spastic esophageal disorders? A systema- tic review and meta-analysis. Dig Dis Sci 2017; 62: 35-44

[4] Bechara R, Ikeda H, Inoue H. Peroral endoscopic myotomy for Jackhammer esophagus: to cut or not to cut the lower esophageal sphincter. Endosc Int Open 2016; 4: E585-E588

\section{Bibliography}

DOI https://doi.org/10.1055/s-0043-115887

Published online: 31.7.2017

Endoscopy 2017; 49: E254-E255

(C) Georg Thieme Verlag KG

Stuttgart · New York

ISSN 0013-726X

\section{ENDOSCOPY E-VIDEOS}

https://eref.thieme.de/e-videos

口回 Endoscopy E-Videos is a free 然故 access online section, reporting 回: on interesting cases and new techniques in gastroenterological endoscopy. All papers include a high quality video and all contributions are freely accessible online.

This section has its own submission website at

https://mc.manuscriptcentral.com/e-videos 